\title{
Integrating Computer-Assisted Language Learning into ESL Classroom: Formation of Moral and Aesthetic Values
}

\author{
A. Bobunova, M. Sergeeva, and E. Notina
}

\begin{abstract}
Information and communication technologies (ICT) have given a modern teacher a powerful incentive for his own professional and creative development, as well as improved the quality of educational services provided. The purpose of this paper is to consider revised Bloom's taxonomy as the way to implement the moral and aesthetic education of students by means of computer-assisted language learning (CALL).

The study involved 84 ESL teachers from 10 secondary Moscow schools. The participants were selected from those who engaged students into e-learning effectively. Group 1 (42 participants) was asked to use revised Bloom's taxonomy to have moral and ethical impact on school children. Group 2 (42 participants) consisted of teachers who had to implement the moral and aesthetic component using ICT on their own.

After conducting a semi-structured interview and comparing the collected data of the two groups according to Student's t-test it was found that most of the participants in group 1 expressed a positive opinion about the introduction of revised Bloom's taxonomy in CALL.

The results of the study confirmed that the structuring of electronic resources and students' activity according to Bloom's objectives leads to easier implementation of the moral and aesthetic component in CALL.
\end{abstract}

Index Terms-Computer-assisted language learning, revised Bloom's taxonomy, intercultural competence, moral judgments, aesthetic taste.

\section{INTRODUCTION}

The use of ICTs as tools that help to improve, facilitate and replace human labor has become widespread in the field of education, from its lower to the upper level. The application of CALL forms such as distance learning, podcasting, and social media into ESL Classroom has created an e-learning environment that is rapidly taking place of a traditional learning environment. On the one hand, the use of state-of-the-art-technologies is a kind of stumbling block for educators; on the other hand, it is an interesting challenge for methodologists and members of the scientific community.

Many teachers implement ICT using only the basic functions of electronic products: visibility, transmission and storage of information, a means of control. However, only a small number of them use technologies not only for the formation of communicative competence, but also for the

Manuscript received March 13, 2020; revised October 15, 2020.

Anna Bobunova and Elena Notina are with RUDN University, Moscow, Russia (e-mail: bobunova-as@rudn.ru, notina-ea@rudn.ru).

Marina Sergeeva is with Research Institute of the Federal Penitentiary Service of Russia, Moscow, Russia (e-mail: sergeeva198262@mail.ru). implementation of moral and aesthetic component required by the Russian Federal educational standard. Currently, in Russia, there is no unified approach to the development and application of methods for the human values formation by means of the electronic environment in a foreign language learning course.

Due to the wide spread of CALL and the problems of reflecting a moral and aesthetic component in education, there is a need to revise and improve existing "traditional" methods of foreign language teaching. The paper deals with the idea that combination of modern ICTs and Blooms' taxonomy is a means of successful moral and aesthetic development of schoolchildren The article is a small but important step towards understanding the importance of studying the moral and aesthetic impact of the electronic educational environment.

\section{InCLUSION OF THE MORAL AND AESTHETIC COMPONENT IN CALL}

Some teachers who use ICT for achieving pedagogical goals adhere to the idea of transferring the traditional educational process to the electronic environment while preserving its aesthetic form and moral content. In this regard, implemented methods should contribute to the immersion of a student in a communicative situation with an enhanced moral component [1]. The chosen methods have a positive impact on the emotional state of the person. Internet technologies such as distance learning systems, hypertext, podcasting, social networks and games have received recognition and spread in foreign language teaching for a decade. Their possible roles in implementing moral and aesthetic components are described below.

\section{A. Learning Management System}

Learning management system (LMS) is used in building electronic educational courses for learning foreign languages. LMS, with an appropriate approach, can have a moral impact on schoolchildren. For this purpose, the electronic integrative course should be based not on the performance of repetitive exercises and tests, but on the activation of visual and sound perceptions for more effective assimilation of the moral and aesthetic material. The inclusion of moral and aesthetic tasks in LMS courses contribute not only to the involvement of students in the educational process, but also to their cultural and personal development.

One of the most common LSM in Russia is MOODLE (Fig. 1). Its capabilities make it possible to develop individual courses for teaching and educating students by means of a foreign language and to develop positive communication between students and teachers on the basis of an electronic 
platform [2], [3]. Designing an individual course of study, a teacher has an opportunity to adjust the content of the course taking into account the level of knowledge, individual characteristics of students, their hobbies and the leading type of perception [4].

The MOODLE structure allows a teacher to create a training course in which each section of the curriculum can be accompanied by information about native and foreign cultures, traditions and customs. In the platform forum, a teacher can open discussions with his students on both academic and personal issues, such as social issues, ethics, family and esthetic values. The platform allows a teacher to monitor and evaluate students' works online [5].

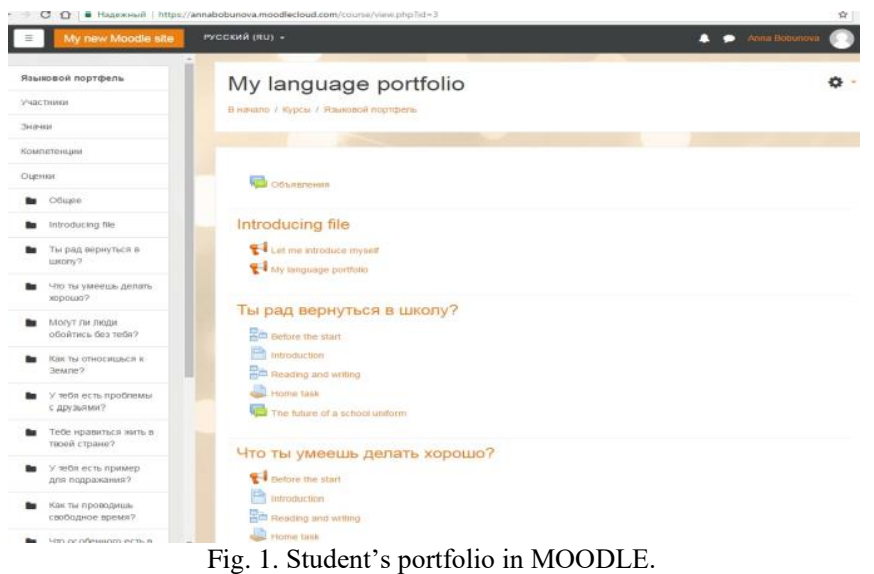

\section{B. Hypertext}

The use of hypertext allows you to expand and enrich the training with new information materials. At the same time, it is important that these materials have moral and aesthetic implications. According to Bakanova the creation of a textbook using hypertext will contribute to the perception and memorization of knowledge at the expense of:

- bright and visual presentation of information; (multimedia, sound, animation, computer graphics, slide shows, etc.);

- integration of a large amount of cognitive information that contributes to the development of cognitive functions;

- expanding opportunities for the presentation of aesthetic samples (films, paintings, poetry, lectures) with the use of video and audio equipment;

- creating an individual trajectory of learning foreign languages [6].

Hypertexts are not only a rich source of information for students of language classes, but also allow them to create their own stories and share them with classmates [7]. They can create their own e-books and magazines. Hypertext can be inserted in illustrations and printed texts. The disadvantages of hypertext, according to Golson, are the possible confusion between the initial text and the content of printed information that occurs when you click on the link, and the inability to perceive the reader hypertext as a full-fledged structure without distraction to external information [8].

\section{Podcasting}

Podcasts are widely used in working with all kind of students. Podcasting allows a teacher to create an individual learning zone for each student. Podcasts are usually divided into authentic and inauthentic, video and audio, self-recorded and external (news reports, weather forecasts, stories, etc.) [9]. The content of the podcasts can produce a particular emotional impact on students depending on podcasts' types and themes.

Authentic podcasts form speech etiquette and represent the culture of native speakers. Correct pronunciation and polite form of speech are well represented in podcasts about culture, interviews with cultural figures and other educated native speakers.

Inauthentic audio texts aimed at listeners around the world or made by non-native speakers also have a positive effect on the formation of auditory skills. Perceiving different accents of English language speakers allow all users, including language learners, to feel as a part of the world community. Most audio guides and podcasts about culture and art are recorded using normative language. They are a good addition to the training course. Correctly formulated task increases the emotional impact on students.

Currently, the use of podcasts in education is limited mainly to listening to recorded audio fragments of speech. Podcasting can not only be a rich source for learning in ESL classroom, but also can transform the idea of creating content that forms a young person in a positive moral way [10], [11]. Podcasting

\section{Games}

Most educational games used for educational purposes are hidden learning technologies that assume that playing students are not aware of the goals set in it by a teacher. Games on serious topics involve participants in solving global world problems (armed conflicts, poverty, hunger, climate change, etc.). The use of fairy-tale characters in educational games increases the motivation of school students to learn physics, chemistry, foreign language and other subject.

The use of games can involve the audience in a variety of virtual activities. Teenagers may see brave heroes or activities related to the game as role models. Orlova has identified six barriers to the implementation of educational video games in the classroom. Some of them are associated with negative perception, excessive immersion in the game and refusal to return to the educational process. Another problem is the weak technical and information infrastructure of schools and the limited time to use it. Other barriers arise in the game content itself (e.g., the game environment does not fully support the desired learning goals, or they do not meet state educational standards) [12]. Thus, to ensure the successful inclusion of the game in the educational process, it is necessary to take into account its various restrictions [13].

\section{E. Social Network}

Social networks are the most popular communication platforms among the younger generation, attracting attention by the scale of audience coverage and focus on the individual interests of users. These qualities allow teachers to use them for the following: 
- establishing contacts with foreign-language users, communication with whom gives language practice and motivates to learn a foreign language;

- using both standard and language learning social networks;

- gaining practice of written communication etiquette [14]. Communication in a foreign language on the topics of morality, beauty and world culture contributes to the formation of personality in the intercultural space. Discussion of acute topics of social issues gives an expanded understanding of world problems, ways to solve them by different countries, and leads to an understanding of the need for intercultural interaction [15].

\section{CALL IN THE ESL CLASSROOM}

According to Bloom's concept, the formation of knowledge includes six levels (comprehension, application, analysis, synthesis and evaluation.), known under the term taxonomy [16]. Anderson and Krathwohl revised Bloom's theory, and highlighted the active role of a student in the formation of personal values and self-education (Fig. 2). Simple acts of memorization and understanding turn from fixing the main essence of the received information in memory into a process of interpretation, comparison with experience and transformation for subsequent work [17].

Moral education is a system of forming moral behavior, feelings, and conscience. Developed moral qualities are responsible for humane relations between people. Morality is based on generalized moral principles and norms. Aesthetic education is the process of forming a sense of appreciation of beauty in various spheres of human activity. The aesthetics of life is manifested through emotionality, intelligence and activity. Aesthetic perception deals with a person's imagination, memory, thinking, and speech. The quality of aesthetic education depends on the level of development of mental processes [18]. Bloom's taxonomy can link moral and aesthetic education with academic education due to the similarity of mental processes.

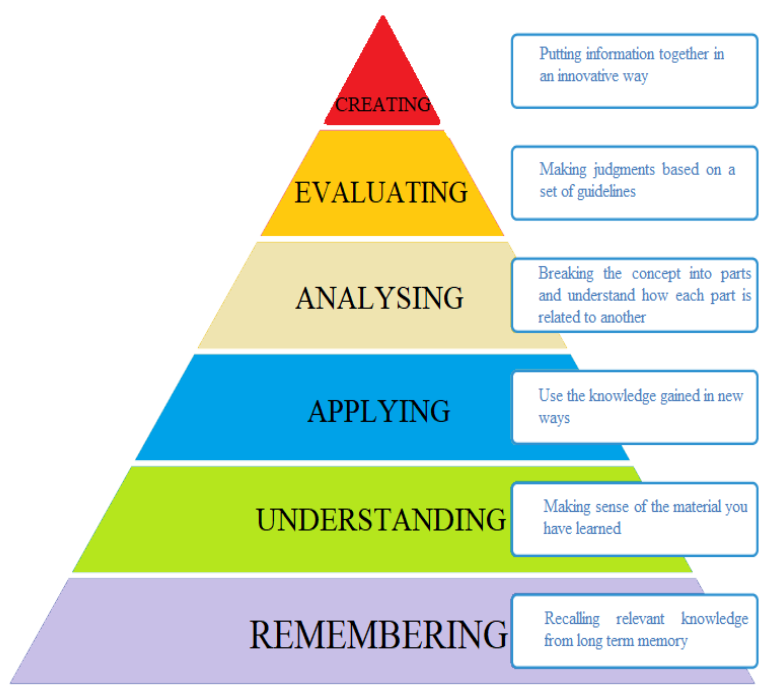

Fig. 2. Revised bloom's taxonomy.

Evaluation, analysis, and synthesis are the essential stages that follow remembering and understanding. Students collect parts of the training material together and evaluate the result. Synthesis helps to apply the obtained material to create new knowledge on the basis of electronic platforms, microblocks with the ability to create bookmarks, organize events and collaborate on a common topic. The Internet environment allows students to share not only photos, music, and movies, but also scientific, linguistic, and cultural materials, making the Internet a world of wide educational opportunities. However, it is necessary to maintain a certain balance between individual creativity and structured learning and collaborative learning activities.

The revised taxonomy makes it possible to implement Bloom's idea in CALL. This structuring of electronic material is necessary for organizing a large number of used accounts, platforms and Internet content of social networks and other web technologies that are used haphazardly and often not only do not contribute to but also clog the educational process (see Table I).

Other social networks and educational platforms, such as Twitter, Facebook, and Moodle, can be used at all the levels of revised Bloom's taxonomy. However, this classification of products can be applied in a different way in the classroom the teacher himself determines which ICT tool is suitable for solving a particular problem. Some examples of work with students aimed at teaching a foreign language and developing moral and aesthetic values are listed below (see Table II)

TABLE I: CHANNELS CORRELATION OF BLOOM'S OBJECTIVES AND ELECTRONIC RESOURCES

\begin{tabular}{ll}
\hline \hline $\begin{array}{l}\text { Bloom's educational } \\
\text { objective }\end{array}$ & Electronic resources \\
\hline Remembering & Flickr, Tumblr, Pinterest, Pixabay \\
\hline Understanding & $\begin{array}{l}\text { Wikipedia, Coursera, Britannica, } \\
\text { Scientificamerican, Freakonomics }\end{array}$ \\
\hline Application & Evernote, Wunderlist, Reddit, Imstagram \\
\hline Analysis & $\begin{array}{l}\text { Google Earth, Data.worldbank, } \\
\text { World-statistics }\end{array}$ \\
\hline Evaluation & Portfolio, YouTube \\
Creation & Wikispaces, Edmodo, Prezi, etc. \\
\hline \hline
\end{tabular}

TABLE II: BLOOM's OBJECTIVES AND STUDENT ACTIVITIES

REMEMBERING

- view photo, audio, and video material that has a moral or aesthetic orientation

- identify the vocabulary that the author uses to enhance the emotional impact

- find examples of speech etiquette

- mark posts on specific topics using tweets, messages, pins, etc.

\section{UNDERSTANDING}

- translate the post into another language, paying attention to the nuances of translating emotionally-colored words and regional vocabulary

- follow the speech etiquette of another country.

- analyze the problem using encyclopedias and information resources

- give a report on the studied material 


\section{APPLICATION}

- collect information / photos about the studied problem

- create a post / article about the raised issue using expressive means of a language.

- present your point of view to your classmates using your own posts

\section{ANALYSIS}

- compare your point of view with the ideas from your classmates' posts - analyze classmates ' posts

- discuss the issue and ask questions using social networks, chat rooms, and forums

- indicate the advantages and disadvantages of using a particular solution to a social problem

\section{EVALUATION}

- combine tweets, pins, chat data and posts in a story

- evaluate the quality and informative content of posts

- evaluate the completeness of the problem analysis

\section{CREATURE}

- come up with an event / situation dedicated to a social problem

- choose the social network that is best suited for posting information or podcasts

- create an account / profile / forum and fill it with the relevant information

\section{METHODS}

The study was conducted qualitatively. 84 ESL teachers from 10 secondary schools in Moscow took part in the survey. The selection of teachers was not random. There was a demand for the active use of electronic devices in English dominating traditional methods.

The selected teachers were divided into group 1 and group 2. Use the revised Bloom's taxonomy, aimed at developing linguistic competence and developing moral and aesthetic values, and was assigned to group 1 . Teachers had to include tasks for the development of moral and aesthetic values in each level. Group 2 participants conducted classes using e-learning and had to develop moral and aesthetic values using their own methods.

During the year, group 1 conducted classes, dividing the choice of electronic devices and resources according to the level of revised Bloom's taxonomy. The presentation of the educational material was focused on the following: linguistic skills, intercultural competence and moral and aesthetic values of the student. Students' progress was assessed using the K-W-L model [19]. Table III shows an example of what students should learn and what skills to form in the lesson dedicated to the topic "My example to follow".

Through the 2018-2019 academic year, all respondents were interviewed in a semi-structured interview on the success of implementing revised Bloom's taxonomy in integrating the moral and aesthetic aspect in CALL. A paired Student's t-test was used to compare the data of two groups.
TABLE III: THE ARRANGEMENT OF CHANNELS

\begin{tabular}{|c|c|c|}
\hline$\frac{\mathrm{K}}{\text { WHAT THEY KNOW }}$ & $\begin{array}{c}\text { W } \\
\text { WHAT THEY WANT } \\
\text { TO KNOW }\end{array}$ & $\begin{array}{c}\text { L } \\
\text { WHAT THEY } \\
\text { LEARNED }\end{array}$ \\
\hline $\begin{array}{l}\text { The use of articles with } \\
\text { proper names. } \\
\text { Professions (actor, } \\
\text { artist, paratrooper, etc.) }\end{array}$ & $\begin{array}{lr}\text { Grammar: } & \text { Making } \\
\text { quotes and direct } \\
\text { Vocabulary: dates, } \\
\text { titles, awards Fluency: } \\
\text { American and British } \\
\text { phrases Accuracy: oral } \\
\text { presentation }\end{array}$ & $\begin{array}{l}\text { The use of grammar. } \\
\text { Presentation of } \\
\text { people's } \\
\text { achievements, } \\
\text { quoting their speech. } \\
\text { Accuracy/Fluency }\end{array}$ \\
\hline $\begin{array}{l}\text { Famous people in the } \\
\text { home country and } \\
\text { abroad }\end{array}$ & $\begin{array}{l}\text { Notable people who } \\
\text { make a difference }\end{array}$ & $\begin{array}{lr}\text { Knowledge } & \text { about } \\
\text { great } & \text { scientists, } \\
\text { doctors, generals, } & \text { heroes, art workers } \\
\text { from } & \text { different } \\
\text { countries } & \end{array}$ \\
\hline $\begin{array}{l}\text { Polite phrases in } \\
\text { conversation. } \\
\text { Knowledge of the } \\
\text { country's heroes, } \\
\text { expression of respect } \\
\text { for veterans }\end{array}$ & $\begin{array}{l}\text { Skills to build and } \\
\text { deliver a pathetic } \\
\text { official speech. } \\
\text { Forming a respectful } \\
\text { attitude to the memory } \\
\text { of war heroes }\end{array}$ & $\begin{array}{l}\text { Presentation of a } \\
\text { report dedicated a } \\
\text { person who made a } \\
\text { difference to the } \\
\text { world. } \\
\text { Forming a Patriotic } \\
\text { mood and feeling of } \\
\text { love for the } \\
\text { Motherland, the } \\
\text { desire to be like } \\
\text { heroes to follow }\end{array}$ \\
\hline
\end{tabular}

\section{$\mathbf{H}$}

HOW THEY LEARNED IT

1. Getting information from a teacher (IQboard)

○ View images (Pinterest)

- Listening to recordings

- Watching video

2. Search and learn new information on the Internet (Wikipedia)

3. Creating your own podcast on a topic (YouTube)

4. Presenting and discussing a podcast with a ESL learners (Facebook, Moodle, YouTube

5. Assessment of podcasts made by classmates (Moodle)

6. The establishment of the international Patriotic school project "My example to follow" (Wikispaces)

\section{RESUlTS}

The analysis of the obtained data shows that the respondents of group 1 stated the simplification in the structuring of educational material, as well as the success of the implementation of tasks for the development of moral and aesthetic values. Respondents noted that the control over the formation of checking values had also been simplified. A large percentage of respondents reported about the manifestation of moral judgments and aesthetic tastes among students during the CALL course.

Based on the recorded data after completing the course, we observed clear changes in some of investigated parameters. $90 \%$ respondents in group 1 indicated the development of moral judgement in comparison with group 2 respondents ( 38 vs. 25 ). $83 \%$ of group 1 participants observed increased aesthetic interest (35 vs. 27) However, the difference in the formation of linguistic skills and intercultural competence between studied groups was not statistically significant (40 vs. 41) and (40 vs. 39) (see Table IV). 
TABLE IV: VARIABLES AFTER COMPLETING THE COURSE IN GROUP 1 AND GROUP 2

\begin{tabular}{|c|c|c|c|c|c|c|c|}
\hline \multirow[t]{2}{*}{ Group } & & & & \multicolumn{4}{|c|}{ T-Value } \\
\hline & $\begin{array}{l}\text { Ј̃ } \\
\text { 音 } \\
\text { z }\end{array}$ & t。 & 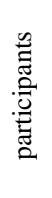 & 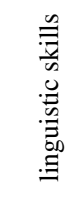 & 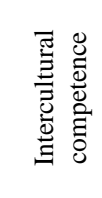 & 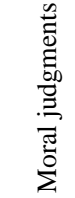 & 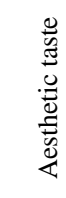 \\
\hline Group 1 & & 42 & & 40 & 40 & 38 & 35 \\
\hline Group 2 & & 42 & & 41 & 39 & 25 & 27 \\
\hline \multirow[t]{2}{*}{ P-values } & & & & $>$ & $>$ & $\leq$ & $\leq$ \\
\hline & & & & 0,05 & 0,05 & 0,05 & 0,05 \\
\hline
\end{tabular}

During to the interview group 2 participants noted some possible chances of implementing moral and aesthetic education using CALL, but most of them agreed with the priority of traditional methods (not electronic). In the survey, more than half of the teachers in group 2 had difficulties in structuring ICT in CALL. However, all participants in groups 1 and group 2 noted an increase in the level of language competence when implementing CALL in ESL classroom.

\section{CONCLUSION}

Having extensive information and creative potential and opportunities for communication and educational interaction, electronic resources help to strengthen the pedagogical impact by activating the independent work of students, their focus on getting a specific product, developing and promoting their ideas in a foreign language. By promoting higher-order thinking, applying revised Bloom's taxonomy help teachers maintain a balance between control and student autonomy without exposing them to extensive network influence. In addition, tasks based on revised Bloom's taxonomy are more consistent because of combination traditional learning methods and ICT. The most of investigated teachers had positive opinion about the use of revised Bloom's taxonomy in CALL for the formation and monitoring of school students moral and aesthetic values and structuring electronic resources and material.

\section{CONFLICT OF INTEREST}

The authors declare no conflict of interest.

\section{AUTHOR CONTRIBUTIONS}

$\mathrm{AB}$ developed the idea of research and designed its test. MS conducted a survey and statistical analysis of data. EN prepared the theoretical base of research.

\section{REFERENCES}

[1] Z. Yechun, "A study on ESL teachers' intercultural communication competence," English Language Teaching, vol. 10, pp. 229-235, 2017.
[2] L. F. Ziangirova, "Development of a distance course based on MOODLE technology," Actual Problems of Humanities and Socio-Economic Sciences, vol. 8, pp. 25-28, 2017.

[3] S. A. Smirnov, Application of Moodle 2.3 for the Organization of Remote Support of the Educational Process, Handbook, Moscow, Russia: School of the Future, 2012, p. 182.

[4] A. N. Afanasiev, "Expanding the interactive capabilities of e-learning based on Moodle: Search and solutions," Education, vol. 7, pp. 4-11, 2016.

[5] O. A. Mineeva et al., "Organization and implementation of current control in teaching a foreign language with the help of LMS MOODLE," Philological Sciences. Questions of Theory and Practice, Tambov: Gramota, vol. 67, pp. 210-212, 2012.

[6] M. V. Bakanova, "Hypertext technology as a means of creating electronic textbooks in a foreign language," PSPU Bulletin, vol. 12, pp. 127-129, 2008.

[7] E. Golson, "Student hypertexts: The perils and promises of paths not taken," Computers and Composition, vol. 12, pp. 295-308, 1995.

[8] K. Beatty, Teaching and Researching Computer-Assisted Language Learning, Second edition, London Pearson Education Limited, 2010, $234 \mathrm{p}$.

[9] P. V. Sysoev, "Modern educational Internet resources in teaching a foreign language," Foreign Languages in School, vol. 6, pp. 2-9, 2008.

[10] A. O'Brien, "Integrating CALL into the classroom: The role of podcasting in an ESL listening strategies course," The Journal of the European Association for Computer Assisted Language Learning, vol. 19, no. 2, pp. 162-180, 2007.

[11] G. Russell, "Elements and implications of a hypertext," Computers \& Education, vol. 31, no. 2, pp. 185-193, 1998.

[12] O. V. Orlova, "Gamification as a way of organizing training," TSPU Bulletin, vol. 9, no. 162, pp. 232-235, 2015.

[13] M. Thomas, H. Reinders, and M. Warschauer, Computer-Assisted Language Learning, London Bloomsbury Academic Bloomsbury Publishing, 2013, p. 194.

[14] A. G. Solomatin, "Social networks as a tool to improve motivation to learn foreign languages," Prospects of Science and Education, vol. 2, no. 32, pp. 231-235, 2018.

[15] A. Chisega-negrila and L. Kraft, "Social networking for esl learners," in Proc. the 11th International Scientific Conference e-Learning and Software for Education, 2015.

[16] Taxonomy of Educational Objectives, Handbook 1: Cognitive Domain, Longman, London, 1956.

[17] L. W. Anderson, D. R. Krathwohl, A Taxonomy for Learning, Teaching and Assessing: A Revision of Bloom's Taxonomy of Educational Objectives, Complete Edition. New York: Longman, 2001.

[18] M. Avdonina and N. Zhabo, "Cognitive psychological aspect of analytical reading of literary text in a foreign language" in Proc. 6th SWS International Scientific Conference on Social Sciences, pp. 85-93, 2019.

[19] D. M. Ogle, "K-W-L: A teaching model that develops active reading of expository text," Reading Teacher, vol. 39, pp. 564-570, 1986.

Copyright $\odot 2021$ by the authors. This is an open access article distributed under the Creative Commons Attribution License which permits unrestricted use, distribution, and reproduction in any medium, provided the original work is properly cited (CC BY 4.0).

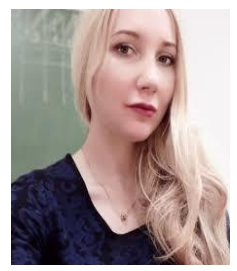

A. Bobunova was born in Vladivostok, Russia, on July 19, 1990. She got the master degree in the field of linguistics and teaching, graduated from Far East State University, Vladivostok, Russia, 2012. She worked as a teacher at public schools, private companies and colleges. Currently she is a senior lecturer at RUDN University, Moscow Russia.

She is interested in the development of moral qualities of ESL learners and integration of ICT and linguistics. Ms. Bobunova is a member of the committee conducting linguistic competitions among Moscow secondary schools.

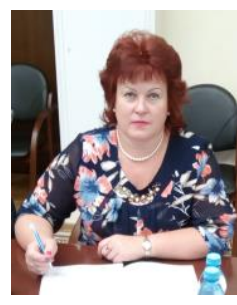

M. Sergeeva was born in Leningrad, Russia, on January 02, 1962. She got the doctoral degree in the field of pedagogy, Institute of educational development strategy of the Russian Academy of education (Moscow) 2013.

She is professor of the foreign languages institute (RUDN University). Currently she is a professor of the research Institute of the Federal penitentiary service of Russia (department of development of 
methodologies for social, psychological, educational and pedagogical work with convicts)

She is interested in the development of creative activity of ESL learners and a personality development in modern societies.

Prof. Sergeeva is a corresponding member of the International Academy of education (Great Britain, London). Winner of the International competition "Best scientific book-2017".
E. Notina was born in Moscow, Russia, on October 18 , 1951. She got the Phd in the field of philology, Peoples' friendship university of Russia (Moscow), 1989.

She is professor of the foreign languages department. Currently she is a Head of the Foreign Languages Department (RUDN University).

She is interested in the development of foreign language competence of university and school students. Prof. Notina is a member of Russian Union of Translators and member of the Scientific Council of RUDN University. 